\title{
Development and Fabrication of a Bi-2223 Racetrack Coil for Generator Applications
}

\author{
Kenneth G. Herd, Lembit Salasoo, E. Trifon Laskaris, Richard A. Ranze, and Christopher G. King \\ GE Corporate Research \& Development Center, Schenectady, New York
}

Pradeep Haldar and Jamie G. Hoehn

Intermagnetics General Corporation, Latham, New York

\begin{abstract}
The development and fabrication of a layer-wound, epoxy-impregnated Bi-2223 hightemperature superconducting (HTS) racetrack coil which generates 40,000 ampere-turns of magnetomotive force (MMF) at $25 \mathrm{~K}$ is described. The coil was wound using Ag-sheathed Bi-2223 tape conductor laminated with copper foils for strength enhancement and insulated using a paper-wrap method. After epoxy impregnation, the coil was tested over a range of $16-25 \mathrm{~K}$ in a vacuum dewar using a closed-cycle helium refrigeration system. Descriptions of the tape lamination and insulation processing, the coil winding and impregnation, and the experimental test setup are given.
\end{abstract}

\section{INTRODUCTION}

This paper describes the development and testing of a prototype Bi-2223 HTS racetrack coil, part of a DoEsupported Superconductivity Partnership Initiative (SPI) to evaluate the use of HTS windings in a 100 MVA utilityscale generator.

The basic geometry of the racetrack coil is shown in Fig. 1. The coil is layer-wound with approximately 2000 meters of Ag-sheathed $\mathrm{Bi}-2223$ tape produced by Intermagnetics General Corporation (IGC). The IGC tape was solder-laminated with $0.008 \mathrm{~cm}$ copper foil on both sides for added strength and then paper insulated prior to winding. Twenty-three discrete lengths of the $\mathrm{Bi}-2223$ tape were joined together using solder splices to form a continuous winding. The finished coil consists of 51 layers with 23 turns per layer, yielding a total of 1165 turns.

A heat exchanger was wrapped around the outer surface of the coil and then overbanded with fiberglass cloth. This coil assembly was then vacuum-pressure impregnated using a low-viscosity epoxy to produce a mechanically robust potted coil structure with the heat exchanger bonded to the coil outer surface.

The coil assembly was suspended in a vacuum dewar and cooled to a temperature of $16 \mathrm{~K}$ using a prototype closed-cycle helium gas refrigeration system, described in [1], which circulates cold helium gas from the refrigerator through the coil heat exchanger.

The coil was first ramped to 30 amperes of current $(-35,000$ ampere-turns MMF) and the coil stabilized at a temperature of $20 \mathrm{~K}$. The coil was subsequently ramped to 34 amperes $(-40,000$ ampere-turns $M M F)$ and the coil stabilized at a temperature of $25 \mathrm{~K}$.

Manuscript received August 27, 1996.

This work was supported in part by the U.S. Department of Energy under Contract No. DE-FC02-93CH10589
The development of the SPI HTS racetrack coil progressed in three distinct phases:

A. Bi-2223 tape lamination and insulation.

B. Racetrack coil fabrication and impregnation.

C. Test dewar and refrigeration setup.

The following sections describe these three phases in detail and discuss the design and processing issues addressed in each phase.

\section{DISTAIBUTION OF THIS DOCUMENT IS UNLIMITED}

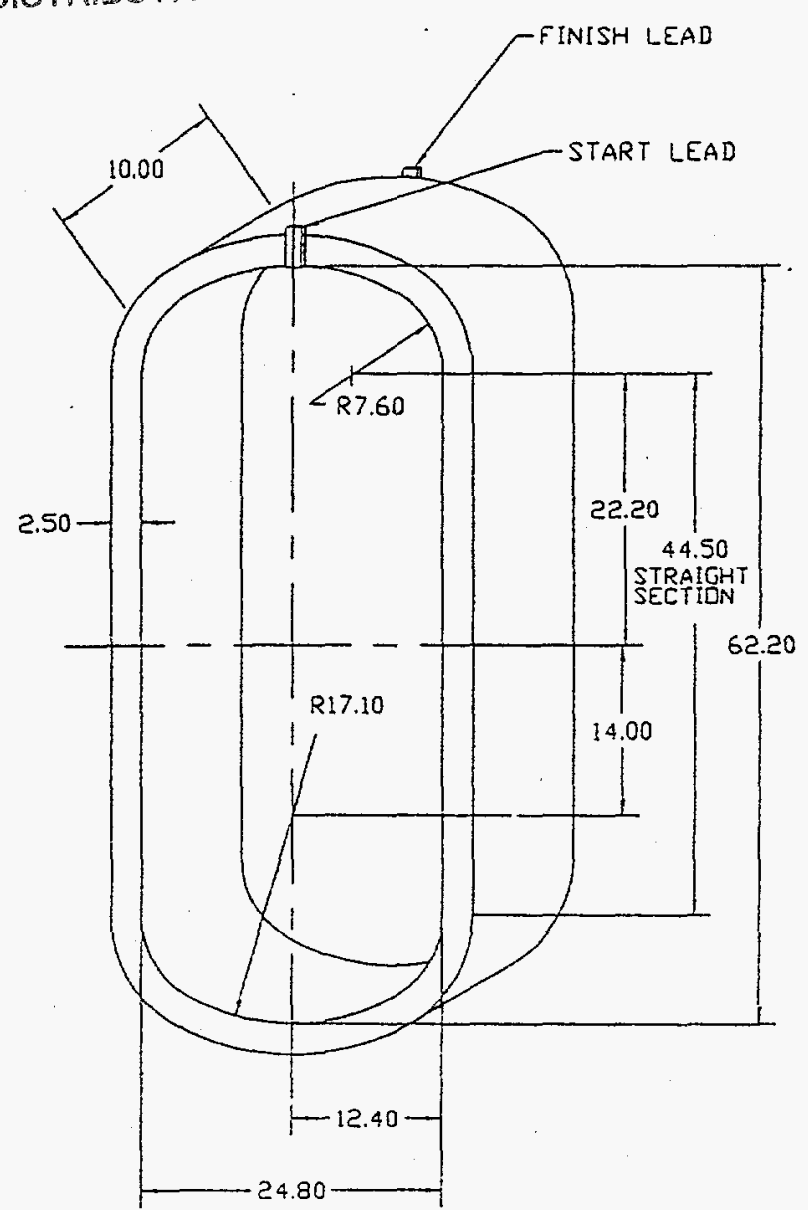

DIMENSIONS ARE IN CM.

Fig. 1. The basic geometry of the racetrack coil is shown. The coil consists of approximately 2000 meters of Bi-2223 HTS tape ing winding with 51 layers, 23 tums/layer, 1165 total turns. 


\section{DISCLAIMER}

Portions of this document may be illegible electronic image products. Images are produced from the best available original document. 


\section{DESCRIPTION}

\section{A. Bi-2223 Tape Lamination and Insulation}

Approximately 3300 meters of $\mathrm{Bi}-2223$ tape were produced by IGC for the SPI program. The annealed Ag stabilizer in these tapes adds very little strength to the conductor, limiting the winding tension for the bare conductor to less than $0.5 \mathrm{~kg}$. Using a process developed at $\mathrm{GE}$ for laminating $\mathrm{Nb}_{3} \mathrm{Sn}$ tapes [2], [3], the $\mathrm{Bi}-2223$ tapes were solder-laminated with $0.008 \mathrm{~cm}$ spring-hard copper foils to both sides of the tape.

The tape critical currents were slightly degraded during the lamination process due to strain effects. However, these reductions were much less than the potential degradation to the bare $\mathrm{Bi}-2223$ tapes during winding and handling. Table 1 lists the critical currents at $77 \mathrm{~K}$ for the 23 discrete lengths of tape, before and after lamination.

\section{TABLE 1}

\section{BI-2223 TAPE CRITICAL CURRENTS AT 77K}

\begin{tabular}{lllll}
\hline Lot Number & $\begin{array}{l}\text { Length } \\
(\mathrm{m})\end{array}$ & $\begin{array}{l}\text { Ic-before } \\
(\mathrm{A})\end{array}$ & $\begin{array}{l}\text { IC-after } \\
(\mathrm{A})\end{array}$ & $\begin{array}{l}\% \\
\text { Degrad. }\end{array}$ \\
\hline 863M11A-P2 & 64.6 & 27.6 & 24.0 & 13 \\
857M11B & 124.0 & 19.6 & 17.6 & 10 \\
$855 \mathrm{M} 1 \mathrm{Al}$ & 93.9 & 28.4 & 19.6 & 31 \\
805M5A & 66.5 & 29.2 & 15.0 & 49 \\
$810 \mathrm{M5}$ & 83.8 & 25.2 & 14.0 & 44 \\
868M11B & 41.2 & 18.8 & 15.0 & 20 \\
809M5 & 85.3 & 26.0 & 18.4 & 29 \\
849M5B & 134.1 & 28.0 & 20.2 & 28 \\
863M11A-P1 & 61.0 & 27.6 & 18.0 & 35 \\
824M5B & 51.2 & 24.0 & 20.0 & 17 \\
852M11A & 104.6 & 28.0 & 18.8 & 33 \\
902M11B & 136.2 & 16.8 & 14.4 & 14 \\
900M11B & 156.7 & 22.0 & 18.4 & 16 \\
900M11A & 184.0 & 26.8 & 19.0 & 29 \\
899M11B & 122.5 & 16.8 & 16.1 & 10 \\
902M11C & 121.9 & 19.6 & 15.0 & 23 \\
899M11A-P1 & 97.5 & 16.8 & 15.4 & 8 \\
856M11C-P1 & 130.5 & 22.0 & 16.6 & 29 \\
898M11C & 127.4 & 17.6 & 16.0 & 9 \\
880M11B2 & 29.9 & 25.2 & 21.0 & 17 \\
878M11B & 100.3 & 26.0 & 20.0 & 23 \\
802M5 & 99.9 & 26.0 & 12.8 & 51 \\
884M11A & 107.9 & 27.2 & 22.8 & 16 \\
\hline Total (Avg.s) & 2325.0 & $(23.7)$ & $(17.7)$ & $(25)$ \\
\hline
\end{tabular}

An average critical current degradation of $25 \%$ was incurred during the lamination process. A detailed description of the lamination process optimization for the $\mathrm{Bi}-2223$ tapes is given in [3].

The lengths listed in Table 1 include all of the tape used in the coil, in the order of usage. Approximately 300 meters were culled out of these lengths due to solder inclusions, excess camber in the tape, or delaminated sections. Eighteen additional lengths of tape with critical currents less than 12 amperes at $77 \mathrm{~K}$ after lamination are not listed in the table and were not used in the coil.
Strain sensitivity measurements were made on the $\mathrm{Bi}$ 2223 tapes before and after lamination. Fig. 2 shows the measured critical currents at $77 \mathrm{~K}$ versus the tensile strain applied to the samples. The results show irreversible strain degradation initiating at $0.10-0.12 \%$ strain for the bare $\mathrm{Bi}$ 2223 samples. Irreversible strain degradation initiates at $0.18-0.24 \%$ for the copper-laminated samples. This represents approximately a twofold increase in the allowable tensile strain for the laminated tapes, corresponding to a fourfold increase in the allowable winding tension (due to the additional cross-sectional area and higher elastic modulus of the spring-hard copper foils).

After lamination the Bi-2223 tapes were insulated using a paper wrap method, described in [2]. No measurable degradation to the critical currents occurred during the insulation of the laminated tapes. The paper wrap provides good layer-to-layer and turn-to-turn insulation after epoxy impregnation and helps to wick the epoxy throughout the coil during the impregnation process.

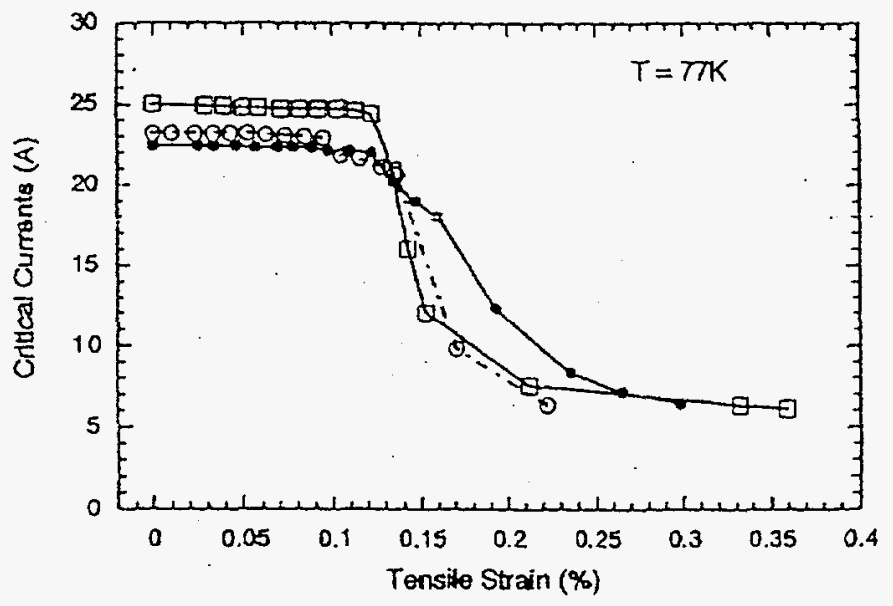

a. Before lamination.

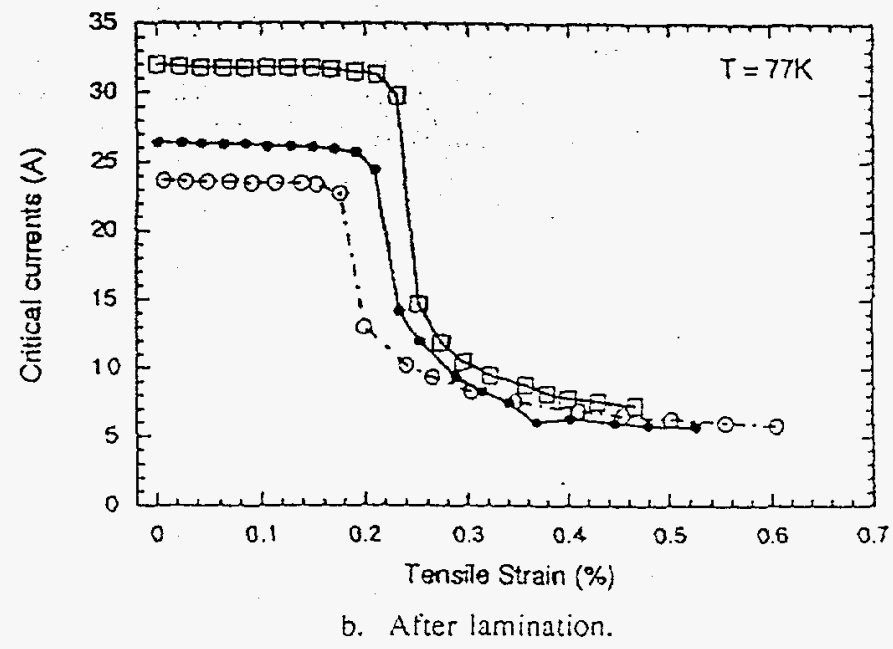

Fig. 2. Strain sensitivity measurements made on the $\mathrm{Bi}-2223$ tapes betore and after lamination show that the allowable strain has been increased twotold, corresponding to a fourfold increase in the allowable winding tension. (Data courtesy of $M$. Suenaga of Brookhaven National Laboratory). 


\section{B. Racetrack Coil Fabrication and Impregnation}

Fig. 3 illustrates the stainless steel mandrel geometry. A hub at the central axis of the mandrel was mounted in the chuck of the winding machine, which controlled the rotation of the mandrel. The tape payoff spool was controlled by a low-tension de-reeler, which synchronized the spool and mandrel rotations and applied a $1 \mathrm{~kg}$ tension to the tape as it was fed onto the mandrel. A traverse arm controlled the pitch of the turns and reversed the winding direction at the end of each layer.

The first length of laminated $\mathrm{Bi}-2223$ tape was soldered to a copper start-lead which was embedded flush to the winding surface and the side plate. At the end of each length of Bi-2223 tape a $5 \mathrm{~cm}$ overlap solder splice was made to the next tape length using a fixture to hold the ends together while heat and lead-tin solder were applied. The splices were all located in the coil end-turn region. The last length of tape on the outermost layer was soldered to a copper finish lead.

As shown in Fig. 3, a heat exchanger was wound around the outer surface of the coil. The heat exchanger consists of a $0.16 \mathrm{~cm}$ thick by $10 \mathrm{~cm}$ wide copper sheet with a single stainless-steel tube brazed to it. The heat exchanger was bent to conform to the coil outer surface and overbanded with $0.6 \mathrm{~cm}$ of fiberglass cloth. The straight sections of the coil and heat exchanger were then compressed using side clamps to minimize any void spaces in the straight sections of the winding and move the conductor slack to the end-turn regions.

Prior to epoxy impregnation, the coil and mandrel were immersed in a liquid nitrogen bath at $77 \mathrm{~K}$ and the coil was ramped to 5 amperes in order to verify the integrity of the conductor, the splices, and the lead connections. A terminal voltage of 41.5 millivolts at 5 amperes was consistent with a theoretical prediction of the coil/tape performance at $77 \mathrm{~K}$, as discussed in [4].
The coil was then potted with a low-viscosity epoxy using a vacuum-pressure impregnation cycle. Heaters and thermocouples embedded in the mandrel were used to control the temperature of the winding during the initial bakeout, pressure cycling, and epoxy cure cycle.

\section{Test Dewar and Refrigeration Setup}

After impregnation the coil was removed from the winding mandrel and suspended from a vacuum dewar lid using four fiberglass rods. The heat exchanger tubing was welded to the supply and return lines carrying the cold helium gas stream from the refrigerator cold box via a vacuum-insulated pipe approximately $1 \mathrm{~m}$ long and $8 \mathrm{~cm}$ in diameter.

The coil current leads were thermally anchored to the gas return line using a dielectrically-isolated heat station. The leads were also heat stationed at an intermediate location to a liquid nitrogen reservoir (at $77 \mathrm{~K}$ ). Warmsection leads (connecting $300 \mathrm{~K}$ to $77 \mathrm{~K}$ ) and cold-section leads (connecting $77 \mathrm{~K}$ to $20 \mathrm{~K}$ ) were made of drawn OFHC copper wires and were optimized to minimize the heat leakage to the heat stations at the maximum estimated coil operating current of 40 amperes.

Six calibrated ruthenium-oxide temperature sensors were epoxied to the coil assembly at the following locations: the inner surface of the coil end-turn at the midplane, the inner surface of the end-turn at the edge, on the start and finish lead busbars, and on the supply and return lines connecting to the heat exchanger. The coil assembly was then wrapped with 100 layers of aluminized mylar in order to minimize the radiation heat load from the warm dewar wall to the coil.

The test dewar was then pumped down to approximately $10^{-5}$ torr using a diffusion pump and the feedthroughs and flanges were leak tested using a helium mass-spectrometer before cooldown.

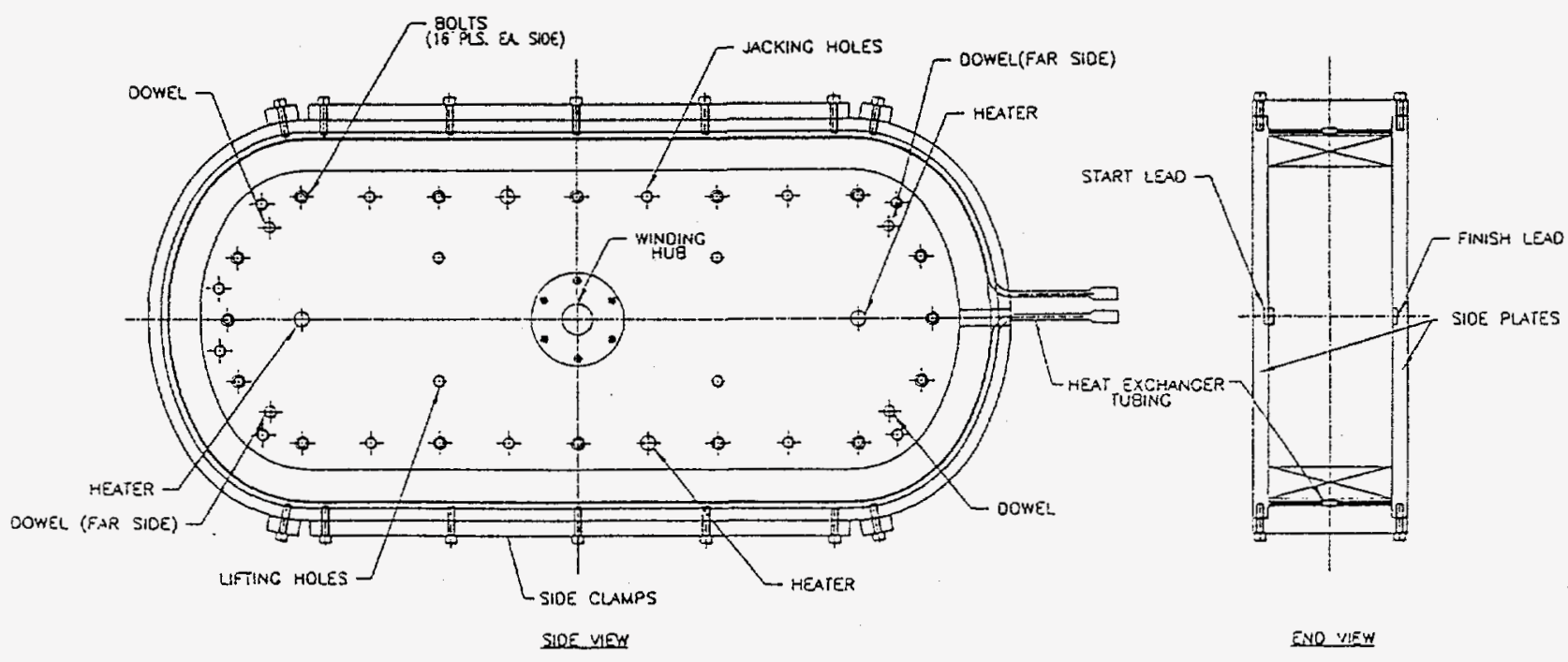

Fig. 3. The aluminum mandrel for the racetrack coil is shown. The hub on the central axis mounts in the winding machine. A heat exchanger is wrapped around the coil and impregnated with the coil to form a monolithic structure. 


\section{TEST RESULTS}

Prior to testing in the vacuum dewar, the potted coil assembly was tested at $77 \mathrm{~K}$ by immersion in a liquid nitrogen bath. Tables 2 and 3 list the measured terminal voltages. ampere-turns, and coil heating for currents up to 15 amperes. The Table 2 measurements are referred to as 'steady-state' results since the terminal voltage reached a stable level. Currents above 9 amperes generated a level of heating in the coil that exceeded the $77 \mathrm{~K}$ surface cooling available, leading to an unstable temperature (and voltage) rise in the coil. The Table 3 measurements are referred to as 'transient', since the voltage was measured for a short period (several seconds) before the current was ramped back to zero. The stable coil heating threshold in the $77 \mathrm{~K}$ bath was in the range of 10 watts.

TABLE 2

STEADY-STATE RAMPING DATA AT 77K

\begin{tabular}{cccc}
\hline Current (A) & Voltage (mV) & $\mathrm{n} *$ I (A-turns) & Heat (W) \\
\hline 1 & - & 1,165 & - \\
2 & 1.5 & 2,330 & 0.004 \\
3 & 4.2 & 3,495 & 0.014 \\
4 & 12.0 & 4,660 & 0.052 \\
5 & 41.0 & 5,825 & 0.21 \\
6 & 119.0 & 6,990 & 0.71 \\
7 & 272.5 & 8,155 & 1.90 \\
8 & 558.0 & 9,320 & 4.46 \\
9 & 1079.0 & 10.485 & 9.71 \\
\hline
\end{tabular}

TABLE 3

TRANSIENT RAMPING DATA. AT 77K

\begin{tabular}{cccc}
\hline Current (A) & Voltage (V) & $\mathrm{n}^{*} I$ (A-turns) & Heat (W) \\
\hline 11 & 2.96 & 12,815 & 18.8 \\
12 & 4.55 & 13,980 & 32.6 \\
13 & 5.82 & 15,145 & 75.7 \\
15 & 10.0 & 17,125 & 147.0 \\
\hline
\end{tabular}

Table 4 lists the measured terminal voltages, ampereturns, coil heating, and coil temperatures for the $20 \mathrm{~K}$ tests. The lead heat stationing to the gas return line, described in the previous section, was implemented for the testing at 20 amperes and above. The coil stabilized at $20 \mathrm{~K}$ with a current of 30 amperes. The maximum stable current level was 34 amperes at a coil temperature of $25 \mathrm{~K}$. Currents in excess of 34 amperes led to a transient (runaway) temperature rise in the coil. Additional transient ramping tests to higher current levels and fast-ramp testing of the coil up to 62 amperes are reported in [4].
TABLE 4

STEADY-STATE RAMPNG DATA AT 2OK

\begin{tabular}{ccccc}
\hline $\begin{array}{c}\text { Current } \\
(\mathrm{A})\end{array}$ & $\begin{array}{c}\text { Voltage } \\
(\mathrm{mV})\end{array}$ & $\begin{array}{c}\mathrm{n}^{*} \mathrm{I} \\
(\mathrm{A} \text {-tums })\end{array}$ & $\begin{array}{c}\text { Heat } \\
(\mathrm{W})\end{array}$ & $\begin{array}{c}\text { Coil } \\
\text { Temp. (K) }\end{array}$ \\
\hline 5 & - & 5,825 & - & 18.6 \\
10 & 1.5 & 11,650 & 0.015 & 18.6 \\
15 & 3.0 & 17,475 & 0.045 & 18.6 \\
20 & 8.0 & 23,300 & 0.16 & 18.7 \\
25 & 10.0 & 29,125 & 0.25 & 19.1 \\
30 & 50.0 & 34,950 & 1.30 & 20.2 \\
34 & 100.0 & 39,610 & 3.40 & 25.1 \\
\hline
\end{tabular}

\section{SUMMARY}

The development and fabrication of a Bi-2223 racetrack coil for generator applications has been completed. IGC has demonstrated the capability to produce $100 \mathrm{~m}$ lengths of $\mathrm{Ag}$-sheathed $\mathrm{Bi}-2223$ tape reliably and consistently. Lamination and insulation processes have succeeded in improving the strength, handling, and winding characteristics of the Bi-2223 tape.

Low-resistance solder splicing of individual tapes to form a continuous winding of more than a thousand turns has been demonstrated. Using a low-tension winding system, laminated and insulated $\mathrm{Bi}-2223$ tapes can be used in layer-wound racetrack coil geometries of appreciable size.

The implementation of a helium gas-cooled heat exchanger to conduction-cool an epoxy-impregnated HTS coil has also been demonstrated for the first time. The remote siting of a refrigerator coldbox with insulated transfer lines connecting to the coil is the first step towards demonstrating the helium gas refrigeration of a rotating HTS coil.

\section{REFERENCES}

[1] K. G. Herd, "Remote Cooling System for a Superconducting Magnet", U.S. Patent 5,485,730, Jan. 1996.

[2] C. King, K. Herd, T. Laskaris, and A. Mantone, "Evaluation of a Strengthening and Insulation System for HighTemperature BSCCO-2223 Superconducting Tape", Intemational Cryogenic Materials Conference, Columbus, Ohio. 1995.

[3] C. King, D. Grey, A. Mantone. K. Herd, and T. Laskaris, "Mechanical Stabilization of BSCCO-2223 Superconducting Tapes", 1996 Applied Superconductivity Conference, Paper MT-9, Pittsburgh, PA, August 1996.

[4] L. Salasoo, K. G. Herd, E. T. Laskaris, H. R. Hart, and M. V. K. Chari, "Test Results for a Bi-2223 HTS Racetrack Coil for Generator Applications", 1996 Applied Superconductivity Conference, Paper LI-7, Pittsburgh, PA, August, 1996.

\section{DISCLAIMER}

\footnotetext{
This report was prepared as an account of work sponsored by an agency of the United States Government. Neither the United States Government nor any agency thereof, nor any of their employees, makes any warranty, express or implied, or assumes any legal liability or responsibility for the accuracy, completeness, or usefulness of any information, apparatus, product, or process disclosed, or represents that its use would not infringe privately owned rights. Reference herein to any specific commercial product, process, or service by trade name, trademark, manufacturer, or otherwise does not necessarily constitute or imply its endorsement, recommendation, or favoring by the United States Government or any agency thereof. The views and opinions of authors expressed herein do not necessarily state or reflect those of the United States Government or any agency thereof.
} 